\title{
An Examination of the Relationship between Death Anxiety, Spirituality, and Quality of Life among Senior Citizens
}

\author{
Shibu Dharmarajan ${ }^{1^{*}}$ and Jasseer Jabbar ${ }^{2}$ \\ ${ }^{1}$ Graduate Programs in Counseling Psychology, Graduate School of Human Sciences, Assumption \\ University of Thailand, Bangkok 10240, Thailand \\ ${ }^{2}$ Department of Psychology, University of Kerala, 695581, India \\ *Corresponding Author.E-mail: sdharamarajan@au.edu \\ https://doi.org/10.12982/CMUJASR.2019.0008
}

\begin{abstract}
Aging is a series of processes which begins with life and continues until death. According to the lifespan, old age is considered as the ending stage in an individual's life. At a certain age, shelhe becomes more vulnerable to disease or illness and this increases the anxieties of being ill and dying. To get a sense of inner peace and overcome anxiety, many of believe that spirituality is a lane leading to holiness, inner peace, and improves the quality of their life. Thus, with these ideas in mind, this investigation examined the relationships between death anxiety, spirituality, and quality of life among elderly citizens. Apart from the above, it is also attempted to find the association of gender differences with the study variables. 120 senior citizens $(N=120)$ participated in this study, and the data were collected by administering the personal data sheet, death anxiety scale, spirituality scale, and quality of life scale. The result of the study demonstrates that death anxiety and spirituality are negatively correlated, whereas spirituality is positively correlated with quality of life. But in the case of gender, there is no significant difference shown in spirituality, death anxiety, or quality of life.
\end{abstract}

Keywords: Death anxiety, Spirituality, Quality of life, Senior citizens

\section{INTRODUCTION}

Senior citizens or elders are old people. They are considered to be wise because they have accumulated valuable experiences over the course of their long lives. According to the perspectives of life span studies, old age is a stage with its own special issues and tasks. Many have retrospectives about their lives, unfulfilled desires, and decide to utilize their existing energies in a fruitful way for the remaining days, months, or years. Old age is considered the ultimate stage of a person's life and it begins around the age of 65 yrs. Some authors labeled it "late adulthood." Many significant developmental changes occur at this stage. Firstly it was noted by Erikson (1959) that it is an important time in a person's life and there exists at during this time of life a conflict between integrity and despair. At this stage, the elder persons will try to find meaning and satisfaction rather than to become bitter and disillusioned.

It is obvious that older persons have more health problems (both mental and physical) than young adults. Most of them have locomotive disabilities due to the deterioration of their health. 
Lots of physical, cognitive, and intellectual changes also occur at this age. Osteoporosis, memory impairment, and reduction in mental abilities are very common among them. Due to the advancement of modern medicine and health care systems, many elderly have extended their lives more than ever before. But in the sense of quality of life, many of them are leading their longer lives with many torments, and this leads to worries of death. Older persons, when they are reaching the end of life, possibly will move through a series of stages in dealing with the ultimate life. During this time they show more attachment to the supernatural powers such as God, or whatever forces of nature, to negotiate and control their fate or try to extend their life for more years. At this stage, many older people are happy and occupied in an array of activities. Ellison and Fan (2008) found an association between spiritual experience and psychological well-being in American senior citizens. Their results revealed that an increase in daily spiritual experiences was associated with $31 \%$ higher chance of not being distressed by thoughts of death. Other shreds of evidence also confirm that the population of senior citizens is rising continuously but they face the important challenges fear of death and death anxiety. This factor has a serious impact on their quality of life. Thus, the present research aimed to find out and uphold the factors that can reduce the agony of death anxiety in the daily life of older people, and support them to improve the quality of their life. (Comment 1 significance of the study)

The Quality of Life (QOL) is a subjective perception of an individual in relation to his or her position in life and the context of the culture and value systems in which he or she lives. It is also connected to their aspirations, outlook, principles, and distress (WHO, 1995). It is further observed that QOL has several dimensions such as physical and mental health, social functioning, and emotional well-being. Barcaccia et al. (2013) stated that QOL is the common well-being of individuals and societies. It is the demarcation of negative and positive features of life. It also denotes happiness from physical health, religious beliefs, family, wealth, education, and employment. At the beginning of the $21^{\text {st }}$ century, elderly research became prominent, and quality of life became one of the key concepts of those researchers (Diener, 2006). Veenhoven (2000) and Noll (2010) distinguished two different traditions in this respect. They indicated the quality of life in terms of objective living conditions and subjective evaluation. Similar distinctions have been made in the context of gerontology as well (Walker, 2005).

Objective quality of life determines a person's command over pertinent assets of his/her life. Health, income, social contacts, and competent skills to act on their goals and direct their living conditions are the determinants of the objective quality of life (Erikson, 1974). Good health, high income, large and reliable social contacts, higher educational qualifications, competence skills are the indicators of the objective quality of life. These can be précised by peripheral spectators. But the other tradition in this regard is the subjective quality of life. It is connected to an individual's perception and evaluations of his life. Based on different internal values and standards the individuals compare their (objective) living situation. This means that people with different aspiration levels may evaluate the same objective situations differently. Campbell, Convers, and Rodgers (1976) reasoned that the subjective quality of life depends on individual person and which lies in the view of the observer. High life satisfaction, strong positive emotions such as happiness, and lower emotions like sadness are the indicators of subjective quality of life, and which can be defined as the subjective well-being of the individuals.

Spirituality is one of the elements that improve quality of life (Crowther, Parker, Achenbaum, Larimore, and Koenig, 2002). It is a collective human experience, something that 
touches all humans. In another way, it signifies the search for the meaning of life. A sacred or transcendent experience or simply a deep sense of aliveness and interconnectedness can be called spiritual experience. Spirituality is a very personal matter which people feel differently about. It has to do with deep feelings and beliefs, both religious and nonreligious, and often involves questions concerning who we are, why we exist, and the purpose of our lives. Today spirituality is one area of interest to psychiatrists and other health care professionals, because they firmly believe that spiritual well-being can bring potential health benefits in the treatment of older people. Spiritual well-being generally means a sense of good health as a whole person and as a unique individual. Some previous studies reported that people who are more spiritual are more likely to proactively take control of health and engage in health-promoting behaviors. In fact, some models of health include spiritual well-being as one component of health-quality of life.

Older persons are closer to spiritual and religious beliefs, so spirituality is a more influential factor in old age or late adulthood. During this period most of them are despair with the inevitability of death and which causes death anxiety among them (Taghiabadi, Kovosi, Mirhafez, Keshvari, and Mehrabi, 2017). To avoid adverse thoughts of death and unpleasant emotions, older persons are more likely to use spirituality to help them adjust in their late adult life (Hoffmann, 2012).

Death can be defined in various ways. According to the physicians or medical terms, death is declared based on vital signs, such as ceasing heart rate and breathing. In psychological terms, death is a complex event that marks the end of life (Feist \& Rosenberg, 2019).

Death anxiety is an individual's apprehension, worries, or fear related to death and dying (Carpenito-Moyet, 2008). But Abdel-Khalek (2005) characterized death anxiety as the apprehension generated by own death awareness. It is also evident from some of the previous pieces ofliterature; death anxiety can adversely affect quality of life. Humans are unique and they are in control of their own life. Hence, they must learn to live and adapt to the consciousness of their own fitness. Spirituality is one of the constituents that can play a key role in the reduction of death anxiety and can, in turn, contribute to the well-being of an individual. By understanding the relationship between these variables, it would be easier to improve quality of life among older persons. It will help them make better adjustments to developmental changes they experience and avoid making situations more severe. This study is expected to shed some light on the changing nature of age-related issues and is also intended to help the family members give more concern to the senior older people at home.

\section{LITERATURE REVIEWS}

Transcendent reality was observed in old age with a spiritual outlook in coping with a variety of life situations by Alfons (1994). It is pivotal to note that, this relationship is a core element of the elderly's global personal well-being. To confirm this, thorough and multiple investigations have been made on the different aspects of death anxiety, spirituality, and quality of life among older persons. A good example is described by Fortner and Neimeyer (1999) in their observation of death anxiety in old age revealed that death anxiety is correlated with age, gender, ego integrity, institutionalization, physical and psychological problems, and religiosity. They claimed with ample evidence that lower integrity, more physical problems, and more psychological problems are the predictors of death anxiety in older persons. 
Related to the quality of life and death anxiety, Sarvimaki and Stenbock (2000) conducted a study based on a population from Finland. They included a sample of 300 subjects aged 75 years. The result of the study proved that there were significant correlations among the variables related to the quality of life and death anxiety. In another investigation by Locker, Matear, Stephens, and Jokovic (2002) tried to assess the oral disorders on the impact of well-being. They targeted a group of older persons was living in long term care centers and the study perpetuates that quality of life, such as morale, perceived life stress, and life satisfaction relates to well-being and satisfaction of life.

To illustrate the direct relationship of spiritual behavior and psychological well-being in older people, Kirby, Coleman, and Daley (2004) conducted a comparative study on spirituality and well-being in frail and non-frail older adults. The results showed that the degree of frailty had a negative effect on psychological well-being. Spirituality was also a significant predictor of psychological well-being and moderated the negative effects of frailty on psychological well-being.

To find the relationship of religion and fear of death in old age, Wink (2006) administered a study among Christian men and women in Northern California, and it is observed that religious believe and practice served as a buffer against death anxiety. In contrast to the above, a positive and direct correlation between financial resources, health and meaning in life and the quality of the life of older persons is obtained in a path analysis by Low, and Molzahn (2007).

Kathleen, Row, and Elliott (2009) predicted the role of religious activity and spirituality in the health and well-being of elderly adults. The results of their studies showed that existential wellbeing is strongly associated with health measures. Apart from this, the influence of psychological well-being, subjective well-being, physical symptoms, and depression can also be foreseen with spiritual well-being. In a study by Hildon, Montgomery, Blane, Wiggins, and Netuveli (2010) noticed a strong positive association between quality of life and life satisfaction index - well-being.

Stanley et al. (2011) examined the relationship between the older adults' preferences for religious and spiritual coping styles toward treatment for anxiety and depression. The findings revealed that the majority of the participants (77-83\%) preferred, including religion and/or spirituality in treatment for anxiety and depression.

In 2014, Velasco-Gonzalez and Rioux acknowledged the forecaster of the spiritual wellbeing of elderly people. The findings created links between the concept of spiritual well-being and the subjective well-being of elderly people. They reasoned spirituality is the righteous approach against materialism and it has the ability to excel in the phase of life. Because the last phase of life fear of death anxiety will be too intense on the elderly, but they overcome this anxiety successfully by leaning into spirituality, and which is considered a path of piousness and inner peace.

According to the Indian context, very few studies are conducted in the area of spirituality, death anxiety, and quality of life. In another exploratory research, Saini, Patidar, Kaur, Kaur, and Kaur (2016) assessed the level of death anxiety and the factors associated with death anxiety among elders in Ludhiana, India. Their results demonstrated that $64.5 \%$ of the elderly showed moderate levels of death anxiety, while 18.5 percent showed severe death anxiety. It is also correlated with medical illness, loneliness, stress related to family, and certain selected demographic variables. Therefore, special care must be given to elderly persons in treatment/care centers.

One of the prominent studies in this regard are related to Budhiraja and Midha (2017). They collected 200 samples from Rohtak city, Haryana (India). The sample included both male and female persons between the age of 60-80 years. The results showed that the level of spirituality and level of death anxiety among the elderly are mutually associated. Further, the correlation 
analysis indicated that there is a negative correlation between spirituality and death anxiety existed. They also claimed that spirituality designates a healing power among elderly persons to overcome the negative thoughts of death.

Kibret and Tareke (2017) examined the status of the psychological well-being of elders' aged 60-89 years. He included existential variables like religious involvement, spirituality, and personal meaning of life along with some demographic factors such as gender, age, and education affecting this status. The results obtained from the study proved that there is a relationship between psychological well-being and the selected variables.

India's culture is among the world's oldest, and India has been identified as the birthplace of both Hinduism and Buddhism. About $84 \%$ of the population identifies as Hindu, and about $13 \%$ of Indians are Muslims, making it one of the largest Islamic nations in the world. Christians and Sikhs make up a small percentage of the population (Clarke, 2013). Religious practices are an integral part of daily life. Hinduism teaches meditation, yoga, and ascetic practices to cultivate selfdiscipline and unity. Irrespective of all religion, most Indians believe that spirituality is an essential part of their life and which will take them to the bliss of happiness to their lives. (Cultural and religious background)

The experience of spirituality, particularly, helps older people think beyond the materialistic world, and here old age is not considered as an end of life, but a preparation for the welcoming of a new life. Thus, keeping these ideas in mind, the present study is attempting to spectacle the relationship between spirituality, death anxiety, and quality of life among senior citizens.

\section{Objectives of the Study}

1. To examine the correlation between spirituality and death anxiety as well as the correlation between spirituality and quality of life among senior citizens.

2. To check the gender-wise differences of the senior citizens in spirituality, death anxiety, and quality of life.

\section{Main hypotheses}

$\mathrm{H1}$ : There is a significant relationship between spirituality and death anxiety.

$\mathrm{H} 2$ : There is a significant relationship between spirituality and quality of life.

H3: There is a significant gender difference among senior citizens in spirituality, death anxiety, and quality of life.

\section{METHODOLOGY}

\section{Sample}

The population of Indian above the age of 60 years was $8.5 \%$ of the total population. The state of Kerala has the highest rate of older adults (13\%) among the Indian states. Being the capital of Kerala, Trivandrum accommodates people from other parts of the state and nation, especially southern states. So the present investigation is designed to study older persons from the capital city of Kerala. (Comment: Rationale for the case selection)

For this research 120 older people (Male $=60$ and Female $=60$ ) of age ranged from 60 to 90 years were selected by using purposive sampling from the selected areas of Trivandrum city, Kerala (India). Due representation was given to gender, educational qualification, family type, religion, monthly income and source of income, and partner alive or not. 


\section{Measures}

Spirituality scale - A self-reporting scale was developed and standardized by Sreekumar and Sanandaraj (2002). Spirituality here refers to the personal, subjective side of religious experience. The scale consists of 26 items, and it is designed to measure the spirituality of people belonging to various religions. A sample of 50 people was selected randomly to determine the split-half reliability. The product-moment formula used to find the correlation between the odd-even items, and a correlation coefficient of 0.83 was obtained. Using the Spearman-Brown formula, the whole test reliability was found to be $0.91(p<0.01)$.

Death anxiety Scale-This scale was developed by Meena and Sanandaraj (1992). The scale consists of 30 items, each measuring different aspects of death or death anxiety. On the answer sheet, the subjects can record their answers in agreement or disagreement way. This is a five-point scale and having an equal number of positive and negative items. The split-half method is used for determining the reliability of the scale. The correlation is calculated using the Pearson-r formula and the correlation is obtained for the scale is 0.80 .Using the Spearman-Brown formula correlation is applied for alteration, and the coefficient of correlation is found to be $0.92(p<0.001)$.

Quality of life scale (QOL) - The World Health Organization (WHO, 1995) developed the quality of life scale. The adapted version of overall quality of life and general health, and four different domains of quality of life: physical, psychological, level of independence, and spiritual or personal beliefs domains (Laiju \& Sanandaraj, 2002). Reliability of the QOL scale was estimated as 0.88 with Cornbach's Alpha test.

\section{Procedure}

The self-reporting questionnaires, along with a personal data sheet, were distributed personally to the subjects. As per the guideline of the ethical committee, the researchers briefed about the study and assured the confidentiality to each participant. An 'informed consent' in writing was obtained from each participant before distributing the questionnaires to them.

Then the subjects were asked to read the questionnaire carefully and choose their responses from the choices, which best describes the way they have been feeling recently and indicate their answers with a tick mark in the response sheet. The subjects were strictly instructed to respond to all of the statements from the questionnaires. 120 samples were collected from the subjects. After verification of the originality of the data, it was subjected to statistical analysis to test the tenability of the hypothesis.

\section{RESULT}

\section{Relationship between spirituality, death anxiety, and quality of life}

Spirituality has been viewed as a positive feature in the lives of senior citizens, which contributes to their emotional, mental, and physical well-being. Spirituality here refers to the personal, subjective side of religious experience. While death anxiety is an anxiety and the cause of which is thoughts of death or it is called thanatophobia occurs in them. Quality of life (QOL) is life satisfaction and general well-being of individuals and societies. It is the exactness with negative and positive features of life and which detects life satisfaction, including all from physical health and social-cultural elements such as family, education, employment, wealth, religious beliefs, finance, 
and the environment. To find out the relationship between spirituality, death anxiety, and Quality of Life in the whole sample $(\mathrm{N}=120)$, the Pearson correlation method is used.

Table 1. Correlation between spirituality, death anxiety, and quality of life in the total sample of senior citizens.

\begin{tabular}{|c|c|c|c|}
\hline Variables & Spirituality & Death anxiety & Quality of life \\
\hline Pearson correlation & 1.000 & $-0.388^{* *}$ & $0.181 *$ \\
\hline \multicolumn{4}{|l|}{ Spirituality } \\
\hline Sig (2-tailed) & & 000 & 015 \\
\hline $\mathrm{N}$ & 120 & 120 & 120 \\
\hline Pearson correlation & $-0.388^{* *}$ & 1.000 & 177 \\
\hline \multicolumn{4}{|l|}{ Death Anxiety } \\
\hline Sig (2-tailed) & 000 & & 310 \\
\hline $\mathrm{N}$ & 120 & 120 & 120 \\
\hline Pearson correlation & $0.181 *$ & 177 & 1.000 \\
\hline \multicolumn{4}{|l|}{ Quality of Life } \\
\hline Sig (2-tailed) & 015 & 310 & \\
\hline $\mathrm{N}$ & 120 & 120 & 120 \\
\hline
\end{tabular}

Note: ${ }^{*} p<0.01$ (2-tailed); ${ }^{*} p<0.05$ (2-tailed)

A significant negative correlation between spirituality and death anxiety is obtained from Table $1(r=-0.388, p<0.01)$. This indicates that, as spirituality increases, death anxiety decreases among the senior citizens. A significant positive correlation between spirituality and quality of life $(r=0.181, p<0.05)$ can be noted from the Table 1 . This means that the spirituality and the quality of lives are moving in the same path. It is also evident from the above table, there is no association between death anxiety and quality of life.

Gender difference in spirituality, death anxiety, and quality of life

To examine the gender difference a t-test was employed. The results of the investigation are tabulated in the Table 2 .

Table 2. Comparison of spirituality, death anxiety, and quality of life among male and female senior citizens.

\begin{tabular}{|c|c|c|c|c|c|c|c|}
\hline Variable & Gender & $\mathrm{N}$ & Mean & SD & $t$-value & Df & Level of sig \\
\hline \multirow{2}{*}{ Spirituality } & Male & 60 & 89.42 & 7.335 & \multirow{2}{*}{.772} & \multirow{2}{*}{118} & \multirow{2}{*}{.053} \\
\hline & Female & 60 & 88.18 & 9.957 & & & \\
\hline \multirow{2}{*}{ Death anxiety } & Male & 60 & 77.67 & 8.898 & \multirow{2}{*}{-1.710} & \multirow{2}{*}{118} & \multirow{2}{*}{.060} \\
\hline & Female & 60 & 80.70 & 10.468 & & & \\
\hline \multirow{2}{*}{ Quality of life } & Male & 60 & 62.95 & 4.865 & \multirow{2}{*}{-1.104} & \multirow{2}{*}{118} & \multirow{2}{*}{.272} \\
\hline & Female & 60 & 65.22 & 15.148 & & & \\
\hline
\end{tabular}




\section{DISCUSSION}

As seen in Table 1, there is a negative relationship between spirituality and death anxiety. This indicates that as spirituality increases in old age, death anxiety diminishes, an that improves their life's quality. This result is consistent with the previous research findings of Taghiabadi, Kavosi, Mirhafez, Keshvari, and Mehrabi in 2017. They reported that there is a direct and converse alliance between spiritual experiences and death anxiety among elders. A similar observation is also found in the study of Kurtulan and Karairmak (2016), who revealed that death anxiety and existential anxiety are negatively correlated with spirituality. Mahboub, Gahrahmani, Shamohammadi, and Parazdeh (2014) investigated a negative association of spirituality and death anxiety in hemodialysis patients. In an earlier study by Rasmussen and Johnson (1994) also argued that spirituality has a significant negative relationship with death anxiety. They further clarified that: death anxiety will decrease due to the degree of certainty with respect to life after death, greater levels of satisfaction with life, and greater feelings of purpose in life. In light of the above studies, it can be argued with confidence that spirituality in senior citizens may bestow a satisfying life review and which may resolve the conflict related to their thoughts of death.

In the case of spirituality and quality of life, Table 1 shows a positive relationship between spirituality and the quality of life of senior citizens. In late adulthood, people will be fond of spiritual beliefs and more attached to God. The previous investigators also paved the way to the above result. For example, in a 2017 study, Pilger, Santos, Lentsck, Marques and Kusumota reported that most of the elder people attained a level of spiritual well-being and which helps them to improve their quality of life as well. They also established a positive relationship between spiritual well-being and quality of life, mostly it was associated with the construct of spiritual well-being. In another study by Krageloh, Billington, Henning, and Chai (2015) also found out a positive relationship between spirituality and quality of life. Saleem and Khan (2015) also highlighted the impact of spirituality on the well-being of elder adults. They also reported that there is a positive correlation between spirituality and well-being. Based on a 2002 study, Crowther, Parker, Achenbaum, Larimore, and Koenig explained the concept of positive spirituality, and offer evidence that links between positive spirituality and health. They summarized the information on a basis for strengthening the existing successful aging model proposed by Rowe and Kahn (1987). They gave ample evidence to suggest that the addition of spirituality to interventions focused on health promotion has been received positively by older adults.

Many older adults experience a number of vulnerabilities related to aging such as an increase in physical, mental, and emotional health issues and significant changes in social and economic status (Berkman, Gardner, Zodikoff, and Harootyam, 2005). However, in the face of these inevitable late-life challenges, spirituality is often identified as a significant source of strength and resiliency in the lives of older adults aged 65 and above. So it can be stated that spirituality in later adulthood improves the quality of life among senior citizens.

From the correlation table, it can also be cited that there is no direct or significant relationship obtained in the case of death anxiety and quality of life.

Regarding gender difference among the study variables, Table 2 indicates that there is no significant difference in spirituality, death anxiety, and quality of life among male and female older people. Some of the previous studies in this field cited some mixed results and they argued religion and culture to be other variables influencing spirituality. Earlier studies carried out in western 
societies claimed that elderly women possess more spiritual orientation than their counter group. Religiosity (religiosity can be considered as a subset of spirituality) however, it has been reported to be more in females than in males in western countries.

Thorson and Powell (1984) noted that females have higher death anxiety than males. They also reported that in late adulthood, the level of death anxiety sags off in contrast with most people's expectations, especially regarding all of the negative connotations about the elderly and the aging process. From the knowledge of the present result, it can be argued that gender is not an element to distinguish death anxiety among senior citizens. Whether male or female, in spite of gender, they are equally anxious about their death.

The World Health Organization takes the view that quality of life is the subjective perception of individuals about their position in life in accordance with the culture and value systems where they live and meet their goals, expectations, standards, and concerns (WHOQOL Group, 1998). From this point of view, in the present investigation into both the male and female senior citizens found themselves to be equal in quality of life. Contradictory to the above findings, some of the previous investigations showed mixed results regarding gender difference in the quality of life. They showed piece of evidence on quality of life and reported females to have more psychological well-being than males, and males reported more physical well-being than females. But Scott et al. (2010) revealed an interesting finding which showed a growing trend of lessening gender difference due to age cohort effects. The pattern showed that there is a lessening of gender difference from people born before 1935 (presently aged 83 and above) and people born about 1020 years later (around the 1950s). The present study has been carried out in a population of older adults in the age range of 60-90 years. Hence, the sample is a mix of individuals born from 19261956 , and this cohort effects could be one of the possible reasons for no gender difference in the present population with regards to the quality of life. The researchers were interested to make a comparison among the three age group of participants viz., 60-69, 70-79, and 80 and above years on the study variables. But the majority of participants belonged to the first group (60-69) and the remaining two groups contain fewer participants. So, the influence of age difference on the wellbeing of older people could not be ascertained.

\section{CONCLUSION}

The objective of this study was to examine the correlation between spirituality and death anxiety as well as the correlation between spirituality and quality of life among senior citizens. The study also attempted to examine the gender-wise differences of the senior citizens in spirituality, death anxiety, and quality of life. The findings showed that there is a negative correlation between spirituality and death anxiety, and a positive correlation also obtained between spirituality and quality of life. However, the study could not find any gender difference in spirituality, death anxiety, and quality of life.

Aging is unavoidable because it is a natural and universal phenomenon. Actually, it is the decisive stage of our life span, where development comes to an end. Most people view, it is a period of decline and degeneration. During the life span, old age is more prominent than the other stages of life. Throughout this period, society perceives them with inactivity and the time of physical and mental decline. With intensive research and experience, gerontologists, who study aging, are have diverse images of the senior citizens. Actually 'age' and 'old age' can be considered a matter of 
prejudiced perception. There is no marked or distinct transformations of physical or intellectual conditions found between middle and old age. In our society, conventionally, the retirement age is viewed as the onset of old age and the elderly feels his/her life is almost over and worries of death begin at this stage.

During old age, the elderly are seized by greater worries about death because they know it is indivisible from their life. These ailments are closely associated with the notion of death anxiety. The study indicates a negative correlation between death anxiety and spirituality. Thus, an increase in spirituality reduces death anxiety. It can, in turn, benefit the quality of life among late adults as a positive correlation is found between spirituality and quality of life.

Understanding these diverse aspects may help to develop strategies to improve the wellbeing of senior citizens. Aging is a journey that includes a spiritual dimension. The spiritual dimension focuses on the meaning of life, hope, and purpose, explored through a relationship with others and with the natural world. The aging population requires person-centered care and developmental support in order to cope with the changes. Present findings can be utilized in health care departments, especially during therapeutic interventions of older people who experience a high level of death anxiety. Spirituality, although a contested concept, is evolving and developing. Hence it is recommended that health care professionals work toward promoting spirituality in reducing the level of death anxiety in elderly persons. Further investigations are needed to address the ways to improve the spiritual dimensions of late adults. In that sense, this study can act as a stimulant for future research in this area.

\section{REFERENCES}

Abdel-Khalek, A. (2005). Death anxiety in clinical and non-clinical groups. Journal of Death Studies, 29(3), 251-259. https://doi.org/10.1080/07481180590916371

Alfons, M. (1994). Spirituality and personal well-being in old age. Ageing \& Society, 14(4), 521-536. https://doi.org/10.1017/S0144686X00001896

Barcaccia, B., Esposito, G., Matarese, M., Berttolaso, M., Elvira, M., \& De Marinis, M.G. (2013). Defining quality of life: a wild-goose chase? Europe's Journal of Psychology, 9(1), 185-203, Psych Open. https://doi.org/10.5964/ejop.v9i1.484

Berkman, B.J., Gardner, D.S., Zodikoff, B.D., \& Harootyam, L.K. (2005). Social work in health care with older adults: future challenges. Families in Society, 86(3), 329-337. https://doi. org/10.1606/1044-3894.3430

Budhiraja, A \& Midha, P. (2017). Buffering power of spirituality against death anxiety. The International Journal of Indian Psychology, 4(2), 59-67. https://doi.org/10.25215/0402.146

Campbell, A, Converse, P.E., \& Rodgers, W. (1976). The quality of American life: perceptions, evaluations, and satisfactions. New York: Russell Sage Foundation.

Carpenito-Moyet, L.J. (2008). Handbook of nursing diagnosis. Philadelphia: Lippincott, Williams and Wilkins.

Clarke, M. (2013). Handbook of research on development and religion. Edward Elgar Publishing Limited, UK. 
Crowther, M.R, Parker, M.W., Achenbaum, W.A., Larimore, W.L., \& Koenig, H.G. (2002). Rowe and Kahn's model of successful aging revisited: positive spirituality - The Forgotten factor. The Gerontologist, 42(5), 613-620. https://doi.org/10.1093/geront/42.5.613

Diener, E. (2006). Guidelines for national indicators of subjective Well-being and Ill-being. Applied Research in Quality of Life, 1, 151-157.

Ellison, C.G. \& Fan, D. (2008). Daily spiritual experiences and psychological wellbeingamong US adults. Social Indicators of Research, 88(2), 247-71.

Erikson, E.H. (1959). Identity and the life cycle: selected papers. Oxford, England: International Universities Press.

Feist, G.J. \& Rosenberg, E.L. (2019). Psychology: Perspectives and Connections. New York: McGrawHill Education.

Fortner, B.V. \& Neimeyer, R.A. (1999). Death anxiety in older adults: a quantitative review. Death Studies, 23(5), 387-411.

Hildon, Z., Montgomery, S.M., Blane, D., Wiggins, R.D., \& Netuveli, G. (2010). Examining resilience of quality of life in the face of health-related and psychosocial adversity at older ages: what is 'right' about the way we age? Gerontologist, 50(1), 36-47.

Hoffman, G. (2012). Basic geriatric nursing. Mosby, Inc.

Kathleen, A., Row, L., \& Elliot, J. (2009). The role of religious and spirituality in the health and well-being of older adults. Journal of Health Psychology, 14(1), 43-52.

Kibret, B.T. \& Tareke, G. (2017). Psychological well-being of elders as a function of religious involvement, spirituality, and personal meaning in life. Clinical and Experimental Psychology, 3, 153. https://doi.org/10.4172/2471-2701.1000153

Kirby, S.E., Coleman, P.G., \& Daley, C.D. (2004). Spirituality and well-being in frail and nonfrail older adults. The Journal of Gerontology, 59(3), 123-129.

Krageloh, C.U., Billington, D.R, Henning, M.A., \& Chai, P.P.M. (2015). Spiritual quality of life and spiritual coping: evidence for a two-factor structure of the WHOQOL spirituality, religiousness, and personal belief module. Health and Quality of Life Outcomes, 13, 26 https://doi.org/10.1186/s12955-015-0212-x

Kurtulan, M.H. \& Karairmak, O. (2016). Examination of the relationship among death anxiety, spirituality, religious orientation and existential anxiety. Spiritual Psychology and Counseling, 1(2), 176-217. https://doi.org/10.12738/spc.2016.2.0007

Laiju, A. \& Sanandaraj, H.S. (2002). Quality of life scale. Thiruvananthapuram: Department of Psychology, University of Kerala, India.

Locker, D., Matear, D., Stephens, M., \& Jokovic, A. (2002). Oral health-related quality of life of a population of medically compromised elderly people. Community Dental Health, 19(2), 9097.

Low, G. \& Molzahn, A. (2007). Predictors of quality of life in old age: a cross-validation study. Journal of Research in Nursing and Health, 30(2), 141-150. https://doi.org/10.1002/nur. 20178

Mahboub, M., Gahrahmani, F., Shamohammadi, Z., \& Parazdeh, S. (2014). Relationship between daily spiritual experiences and fear of death in hemodialysis patients. Journal of Biiology and Today's World, 3(1), 7-11. https://doi.org/10.15412/J.JBTW.01030102 
Meena, M. \& Sanandaraj, H.S. (1992). Death anxiety scale. Thiruvananthapuram: Department of Psychology, University of Kerala, India.

Noll, H-H. (2010). Measuring and monitoring the quality of life. In European University Institute Workshop. Germany: GESIS.

Pilger, C., Santos, RO.P.D, Lentsck, M.H., Marques, S., \& Kusumota, L. (2017). Spiritual wellbeing and ouality of life of older adults in hemodialysis. Rev-Bras Enferm, 70(4), 689-696. https://doi.org/10.1590/0034-7167-2017-0006

Rasmussen, C.H. \& Johnson, M.E. (1994). Spirituality and religiosity: relative relationships to death anxiety. Journal of Death and Dying, 29(4), 313-318. https://doi.org/10.2190/D1M93W6J-FY33-G3HQ

Rowe, J.W., \& Kahn, RL. (1987). Human aging: usual and successful. Science, 237(4811), 143-149. https://doi.org/10.1126/science.3299702

Saini, P., Patidar, A.B., Kaur, R, Kaur, M., \& Kaur, J. (2016). Death anxiety and its associated factors among elderly population of ludhiana city, punjab. Indian Journal of Gerontology, $30(1)$.

Saleem, R, \& Khan, S.A. (2015). Impact of spirituality on well-being among old age people. The International Journal of Indian Psychology, 2(3), 172-181. https://doi.org/10.25215/ 0203.039

Sarvimaki, A., \& Stenbock-Hult, B. (2000). Quality of life in old age described as a sense of wellbeing, meaning and value. Journal of Advanced Nursing, 32(4), 1025-1033. https://doi.org/ 10.1046/j.1365-2648.2000.01568.x

Scott, N.W., et al. (2010). Differential item functioning (DIF) analyses of health-related quality of life instruments using logistic regression. Health and Quality Life Outcomes, 8, 81. https://doi.org/10.1186/1477-7525-8-81

Sreekumar, R. \& Sanandaraj, H.S. (2002). Spirituality Scale and Manual. Thiruvananthapuram: Department of Psychology, University of Kerala, India.

Stanley, M.A, Bush, AL., Camp, M.E., Jameson, J.P., Phillips, L.L, Barber, C.R., ..Chully, J.A. (2011). Older adults preferences for religion/spirituality in treatment for anxiety and depression. Aging Mental Health, 15(3), 334-343. https://doi.org/10.1080/13607863.2010. 519326

Taghiabadi, M., Kavosi, A., Mirhafez, S.R., Keshvari, M., \& Mehrabi, T. (2017). The association between death anxiety with spiritual experiences and life satisfaction in elderly people. Electronic Physician, 9(3), 3980-3985. https://doi.org/10.19082/3980

Thorson, J. A. , \& Powell, F. C. (1984). Revision and factor analysis of a death anxiety scale abstract. Paper presented at the annual scientific meeting of the Gerontological Society, San Antonio, New Mexico.

Veenhoven, R (2000). The four qualities of life. Journal of Happiness Studies, 1(1), 1-39. Kluwer Academic Publishers. https://doi.org/10.1023/A:1010072010360

Velasco-Gonzalez, L. \& Rioux, L. (2014). Spiritual well-being of elderly people: a study of a French sample. Journal of Religion and Health, 53(4), 1123-1137. https://doi.org/10.1007/ s10943-013-9710-5

Walker, A. (2005). A european perspectives on quality of life in old age. European Journal of Aging, 2(1), 2-12. Springer. https://doi.org/10.1007/s10433-005-0500-0 
WHOQOL Group. (1998). Development of the world health organization WHOQOL-BREF quality of life assessment. Social Science and Medicine, 46(12), 1569-1585.

Wink P.(2006). Who is afraid of death? religiousness, spirituality, and death anxiety in late adulthood. Journal of Religion, Spirituality \& Aging, 18(2-3), 93-110. https://doi.org/ 10.1300/J496v18n02_08 